\title{
A NÃO-ORDENAÇÃO FEMININA: DELIMITANDO AS ASSIMETRIAS DE GÊNERO NA IGREJA CATÓLICA A PARTIR DE RAPAZES E MOÇAS VOCACIONADOS/AS
}

\author{
SÍLVIA REGINA ALVES FERNANDES \\ CERIS - Centro de Estatística Religiosa e Investigações Sociais
}

\begin{abstract}
Resumo: A não-ordenação feminina no catolicismo é abordada neste texto a partir da ótica de jovens seminaristas e moças que desejam ingressar em conventos. Trata-se de um estudo sociológico e qualitativo que analisa comparativamente as percepções de rapazes e moças sobre as relações de gênero na Igreja Católica. Suas narrativas demonstram claramente a existência de desigualdades de gênero no nível hierárquico e revelam que as moças tendem a ser mais críticas e questionadoras e os rapazes tendem a manter o status quo.

Palavras-chave: catolicismo, gênero, vocação religiosa.
\end{abstract}

\section{Introdução}

A questão da ordenação sacerdotal para as mulheres no catolicismo é bastante polêmica. Em 1994 João Paulo II lançou a carta apostólica Ordinatio Sacerdotalis ${ }^{1}$ na qual o tema é dado por encerrado a partir de argumentações de caráter teológico que podem ser sintetizadas nos seguintes pontos: a) a missão sacerdotal foi confiada apenas aos homens por Cristo que chamou 12 apóstolos; b) a necessidade ou valorização da preservação da tradição ou da prática da lgreja ao longo dos séculos nesse tema; c) como conseqüência do segundo item, aborda-se a irrevogabilidade do Magistério da lgreja. ${ }^{2}$ Aquele documento irá enfatizar que não se trata de discriminar as mulheres, mas simplesmente de atender a uma certeza inquestionável acerca do mistério de Cristo e de sua lgreja.

Copyright $\odot 2005$ by Revista Estudos Feministas

1 JOÁO PAULO II, 1994

2 Zilda RIBEIRO, 1998, p. 139. 
Para Luiz Alberto G. Souza ${ }^{3}$ essa declaração papal não se revestiu de um caráter solene e dogmático e, nesse sentido, talvez possa ser revisada em tempos não muito longínquos. Entretanto, pode-se observar, sim, um tom de bastante solenidade na declaração papal supracitada, cujo trecho final reproduzo aqui:

Portanto, para que seja excluída qualquer dúvida em assunto da máxima importância, que pertence à própria constituição divina da Igreja, em virtude do meu ministério de confirmar irmãos (cf. Lc 22,32) declaro que a Igreja não tem absolutamente a faculdade de conferir a ordenação sacerdotal a mulheres, e que esta sentença deve ser considerada como definitiva por todos os fiéis da Igreja. ${ }^{4}$

Maria José R. Nunes ${ }^{5}$ assinala que no catolicismo os homens não são apenas detentores do poder sagrado de mediação entre os indivíduos e a divindade através do exercício do ministério sacerdotal, mas além disso são eles que irão elaborar a narrativa oficial em que se naturalizam padrões sobre o que seria inerente ao mundo feminino e o que pertenceria ao mundo masculino.

Desse modo, apesar da prescrição romana, o tema da ordenação sacerdotal feminina no mundo eclesiástico e para a sociedade mais ampla ainda não pode ser dado por encerrado.

A argumentação das teólogas ${ }^{6}$ e feministas católicas acompanha o debate já institucionalizado ${ }^{7}$ a respeito das diferenças de gênero nas sociedades modernas. Tais diferenças são contestadas quando deixam de ser diferenças para tornarem-se desigualdades ou "diferença hierarquizada", conforme a abordagem de Maria Quinteiro" quando analisa que homens e mulheres possuem valores e desejos distintos. Para essa autora, o problema da desigualdade encontrar-se-ia no nível de valorização atribuída socialmente a homens e mulheres.

Há que se levar em conta ainda que as mulheres também reproduzem desigualdades e imprimem na cultura e no comportamento cotidiano traços marcados por uma visão de mundo discriminatória, não sendo os homens os únicos responsáveis pela assimetria de poder em nossas sociedades. Esse movimento foi observado em um estudo realizado com mulheres vinculadas ao Movimento Carismático e mulheres evangélicas. Ali pode-se constatar a existência de constrangimentos das mulheres carismáticas na reivindicação de cargos funcionais no catolicismo. Muitas se adaptam às funções que lhes são outorgadas, restringindo a própria participação a pequenos grupos. ${ }^{9}$

O grande ganho das sociedades modernas com o debate insuflado pelas teorias feministas acerca das relações de gênero foi exatamente a problematização dessas relações, tendo em vista que não há consenso sobre muitas proposições. Assim, o principal objetivo das teorias feministas seria a análise de como os indivíduos "pensam, não pensam ou evitam pensar sobre gênero". ${ }^{10}$

${ }^{3}$ SOUZA, 2004, p. 73.

${ }^{4}$ Cf. DOCUMENTOS PONTIFÍCIOS, 1996

${ }^{5}$ ROSADO NUNES, 1998, p. 11.

- É importante atentar para o fato de que também no campo das teólogas feministas não se pode falar de uma única vertente. Há no mínimo sete elaborações teológicas feministas, quais sejam: teologias feministas brancas, teologias da libertação de mulheres negras, amarelas, mulatas e vermelhas, teologias feministas evangélicas, históricas, teologia das mulheres indígenas, entre outras (ROSADO NUNES, 1998).

${ }^{7}$ Ao mencionar a idéia de existência de um debate já institucionalizado sobre o tema das relações de gênero, levo em conta a consolidação dos ideais propostos pela revolução feminista que constitui uma decisiva revolução social da era moderna. O movimento é também considerado como um "divisor de águas em todas as culturas até agora existentes” (Agnes HELLER e Ferenc FEHÉR, 1998, p. 207).

8 QUINTEIRO, 1996, p. 125.

${ }^{9}$ Maria MACHADO e Sílvia FERNANDES, 2000, p. 150-167.

10 Jane FLAX, 1992, p. 225. 
A palavra gênero implica a consideração das relações sociais no sentido de que ${ }^{11}$ cada ator social carrega consigo um background subjetivo capaz de interagir com elementos objetivos em determinados contextos sociais. Jane Flax ${ }^{12}$ considera que para qualquer pessoa as relações de gênero e a estrutura de gênero em uma perspectiva de categorias sociais são formadas exatamente pelas interações entre relações de gênero e outras, tais como as de classe e raça. Contudo, essa mesma autora argumenta que, para compreender o gênero na perspectiva das relações sociais, será necessário desconstruir os significados atribuídos a biologia/sexo/gênero/natureza e esta não constitui uma tarefa fácil. ${ }^{13}$

Não desconsidero a amplitude do debate que contemporiza a díade dominação masculina/subordinação feminina, mas procuro não utilizar apenas essa lente ao analisar os discursos dos/as vocacionados/as acerca das relações homem-mulher no universo eclesial.

Este texto aborda a opinião de rapazes e moças vocacionados/as no Rio de Janeiro sobre as categorias feminino e masculino na lgreja, considerando os lugares ocupados por mulheres e homens e a questão da ordenação sacerdotal para as mulheres. ${ }^{14}$ Utilizei o método qualitativo de análise a partir da realização de entrevistas em profundidade com um roteiro semi-aberto. Vale ressaltar que os resultados obtidos ajudam a observar tendências que merecerão investigações posteriores.

\section{O lugar da mulher na lgreja e o sacerdócio feminino - visão dos rapazes}

No grupo de rapazes vinculados a seminários diocesanos ${ }^{15}$ encontramos os seguintes posicionamentos: quatro rapazes manifestaram concordância com o posicionamento oficial da lgreja a respeito do tema e outros quatro mostraram-se mais flexíveis afirmando que a posição oficial da lgreja poderia ser revisada. Um seminarista não soube opinar sobre o tema.

Importa destacar que os rapazes afinados com a posição oficial da lgreja pertencem à diocese do Rio e os que relativizam tal posicionamento pertencem à diocese de Duque de Caxias. A opinião dos seminaristas ligados a ordens ou institutos religiosos ${ }^{16}$ apresentou

\footnotetext{
${ }^{11}$ Para Judith BUTLER, 1987, p. 10, a categoria gênero não denotaria um ser substantivo, mas antes um ponto de convergência entre um conjunto específico de relações cultural e historicamente construídas. Também Simone de Beauvoir considera o gênero como um ato diário de reconstrução e representação a respeito do qual somos cobrados cotidianamente se exercermos nossa masculinidade ou feminilidade de forma inadequada, fora das normas de gênero socialmente estabelecidas (BUTLER, 1987).

12 FLAX, 1992.

${ }^{13}$ Jane Flax faz a crítica ao que temos denominado teorias feministas em suas várias vertentes. Para a autora, "o empreendimento da teoria feminista está cheio de tensões e armadilhas. Na medida em que as mulheres fazem parte de todas as sociedades, nosso pensamento não tem como estar livre de modos culturalmente construídos de auto-entendimento" (FLAX, 1992, p. 246).

${ }^{14}$ Trata-se de uma adaptação de um dos capítulos de minha tese de doutorado intitulada "Ser padre pra ser santo; ser freira pra servir": a construção social da vocação religiosa - uma análise comparativa entre rapazes e moças no Rio de Janeiro (FERNANDES, 2004a). Foram entrevistados/as 35 jovens, sendo 19 moças e 16 rapazes em diferentes seminários e congregações religiosas.

${ }^{15}$ Trata-se daqueles que pretendem ser padres para atender a uma diocese e não a uma ordem religiosa tal como os Beneditinos, Franciscanos, etc. Os seminaristas diocesanos atuam em paróquias e, salvo algumas exceções, vivem sozinhos na casa paroquial. Neste estudo entrevistei nove rapazes que pretendem ser padres diocesanos.

${ }^{16}$ Não obtive informações precisas sobre a orientação pastoral ou linha ideológica dos institutos religiosos pesquisados em relação aos temas. Contudo, foi possível perceber na conversa com alguns formadores a existência de posicionamentos mais críticos, seja diante da orientação da diocese do Rio de Janeiro, seja diante da formação dos seminaristas e noviças. Do mesmo modo, um provincial (religioso responsável por uma determinada área geográfica) se mostrou tradicional e os rapazes de sua congregação estudavam no Mosteiro de São Bento, reconhecido por oferecer conteúdos formativos adequados às prescrições romanas.
} 
divergências em menor proporção. Entre os sete rapazes que possuem esse tipo de vinculação, quatro demonstraram concordância com o discurso oficial da Igreja e três apresentaram uma visão menos ortodoxa.

No conjunto dos rapazes entrevistados, tem-se, portanto, oito seminaristas contrários à ordenação sacerdotal feminina e sete favoráveis, o que evidencia uma divisão a respeito do tema. Aqueles que se manifestaram contrariamente fazem uso de argumentos fortemente marcados pela prescrição institucional. Os depoimentos do primeiro grupo de seminaristas diocesanos, ou seja, dos pertencentes à diocese do Rio e consonantes com a prescrição da Igreja a respeito da ordenação feminina, revelam que há uma contumaz ênfase na manutenção da tradição, sendo o argumento da tradição acionado por quase todos.

Vejamos o discurso de um dos jovens que se posicionaram de forma mais ortodoxa em relação à temática. Trata-se de Marcos, um rapaz de 24 anos que afirmara ter sonhado com a carreira militar, dado que justifica sua escolha em ser capelão militar ${ }^{17}$ no momento que sentiu o impulso para a vida sacerdotal. Marcos participou ativamente da Renovação Carismática Católica até iniciar sua formação para a vida sacerdotal. Em geral, ele se manifesta de modo a reforçar a institucionalidade da lgreja. Seu discurso revela valorização da norma e da disciplina:

[..] surge um grande questionamento que as pessoas fazem a respeito da mulher não poder ser ordenada, porque a Igreja, ela conserva aquilo que Jesus andava com os doze apóstolos, não instituiu mulheres [...].É uma decisão da Igreja conservadora, eu gosto dessa linha conservadora [...] pelo que eu vejo são pouquíssimas as mulheres que contestam isso dentro da Igreja, são pouquíssimas, então quem mais contesta é quem está de fora, que jamais teria a coragem de chegar e ser uma celibatária pra consagração a Deus (Marcos, 24, diocesano, Filosofia).

Como se percebe, para Marcos a reivindicação do sacerdócio feminino não parte dos agentes intra-eclesiais, mas sim de pessoas que estão fora da Igreja. Em adição, ele ressalta a importância de preservar "o que Jesus deixou", demonstrando crer fortemente que a orientação dos padres da Igreja segue aquela deixada pelo próprio Cristo.

Em geral, os seminaristas que argumentam mencionando os "dados da Teologia" consideram o que está prescrito nos documentos oficiais da Igreja a respeito da nãoordenação feminina, a saber, o fato de que Jesus não teria incluído nenhuma mulher quando formou o grupo dos apóstolos. É o caso de Flávio, que considera haver um "lugar da religiosa" que o padre não poderia ocupar - ele não explicita concretamente qual seria esse lugar. A realidade eclesial, entretanto, revela que não há restrições ao clero no que se refere à realização de atribuições desenvolvidas pelas religiosas. Nesse caso, esse lugar diferenciado traduzir-se-ia apenas como o lugar, pode-se dizer, canônico, institucionalizado, mas que não inviabiliza o acesso dos clérigos a atribuições das religiosas, tais como os aconselhamentos, as organizações de pastorais paroquiais ou grupos comunitários, as visitas pastorais, a atuação em escolas, entre outras atividades.

A análise do discurso de alguns seminaristas explicita a necessidade de manutenção ou defesa da tradição em um mundo em que ela é posta em xeque cotidianamente. ${ }^{18} \mathrm{~A}$ própria polêmica a respeito das relações de gênero nas sociedades modernas demonstra

\footnotetext{
${ }_{17}$ Os padres capelães militares são responsáveis por oferecer assistência espiritual e moral necessária aos integrantes das Forças Armadas e, em situações oportunas, aos seus familiares. Em geral, atuam em escolas, hospitais e vilas militares.

${ }^{18}$ Uma das teólogas que argumentam a favor da ordenação de mulheres questiona: "Mas justamente a discussão em torno da ordenação de mulheres não mostra melhor do que qualquer outra o fracasso de soluções autoritativamente impostas?" (Ângela BERLIS, 1999, p. 103-11 1). Quase sempre o tema do autoritarismo aflora nesse debate em que a tradição que o justifica é também formulada por homens.
} 
a ocorrência da destradicionalização no sentido atribuído por Anthony Giddens, Ulrick Beck e Scott Lash, ${ }^{19}$ a saber, a mudança de status das tradições, já que estas são constantemente questionadas pelos agentes e instituições sociais. É também Giddens ${ }^{20}$ que nos assegura que até o limiar da modernidade, e ainda posteriormente, os lugares masculino e feminino estavam muito bem afinados e consonantes com a ordem estabelecida e, portanto, não abertos ao exame discursivo. Trata-se, assim, segundo esse mesmo autor, de uma necessidade de "justificação discursiva" que vem à tona em tempos de modernidade avançada. Nesse sentido, destaca-se o processo de intensificação dessas justificativas como forma de legitimação da tradição que já não basta a si mesma enquanto narrativa. Para Giddens, a não-assimilação ou não-reconhecimento dessa mudança de status das tradições aniquilaria as relações sociais, pois essas só podem sobreviver à medida que acolhem e mantêm o espaço discursivo.

Nesse contexto, homens e mulheres são chamados a apresentar as razões ou as justificativas para suas novas identidades, buscando evitar ou minimizar a consolidação de espaços de opressão ou marginalização do outro, em suma, espaços de violência humana.

O elogio à presença das mulheres na Igreja - atitude comum em praticamente todos os seminaristas - permite a avaliação de que, diante do confronto e da pressão feminina (de mulheres das mais diferentes esferas da sociedade), o reconhecimento dos rapazes quanto à presença da mulher pode ser estratégico no sentido de que a lgreja não estaria negando a importância dessa figura em seu corpo social e muito menos a desvalorizando, mas antes concederia à mulher cada vez mais espaço no mundo leigo eclesial. Ressalve-se, por outro lado, que se trata de lugares concedidos, como por exemplo o exercício de alguns 'ministérios' (eucaristia) ou coordenações regionais (assessorias à CNBB, Secretaria de Movimentos), e pouco conquistados a partir de reivindicações femininas, ou seja, os homens da lgreja permitem e regulam que as mulheres ocupem lugares previamente determinados por eles.

Destarte, esse debate não pode ser simplificado a partir de uma hipótese que poderia soar como falsa de que as mulheres reivindicam lugares na hierarquia. Um observador mais atento poderá notar que, ao menos nos espaços paroquiais, muitas mulheres se sentem felizes e realizadas ao servirem os sacerdotes nas celebrações, prestarem um papel suplementar nas secretarias, cuidarem das vestes sacerdotais e objetos litúrgicos e se sentirem responsáveis por alguns serviços que o próprio padre lhes outorga. Assim, quando nossos seminaristas questionam quem afinal são as mulheres que reivindicam espaços na hierarquia, eles certamente têm em mente as senhoras que convivem com os padres nas paróquias. Muitas delas optam por dedicar menor tempo à família nos fins de semana para estarem a serviço da lgreja e, por que não dizer, do bem-estar do padre.

Por outro lado, não se pode negar que existam insatisfações, ${ }^{21}$ como os depoimentos das moças e de alguns seminaristas também nos revelam. Esse dado sinaliza para a relevância de ampliação da categoria gênero na medida em que se leva em conta o

\footnotetext{
19 GIDDENS et al., 1997.

20 GIDDENS, 1997, p. 129.

${ }^{21}$ Em recente assessoria que prestei a uma assembléia diocesana onde o público era composto por bispos, padres, leigos e religiosas, toquei nessa temática no sentido de questionar como as relações de gênero têm sido vividas no cotidiano paroquial. Ao final, duas mulheres, uma freira e uma leiga, agradeceram-me a palestra e afirmaram a ocorrência de centralização de poder nas mãos dos párocos e bispos.
} 
contexto que alguns analistas denominam de pós-modernidade. ${ }^{22}$ Quais seriam as diferenças possíveis de serem estabelecidas entre "Mulher" e "mulheres"? A diversidade que se deve levar em conta na utilização da categoria mulheres deve supor o entrecruzamento entre outras variáveis sociais tais como classe e raça, sem isolar a categoria gênero. Nesse sentido, coloca-se a necessidade de tratar a questão de gênero de forma mais abrangente, de modo que não esteja restrita simplesmente à configuração de um feminino e de um masculino, mas de femininos e masculinos que se interpenetram e se constituem complexos em si mesmos. A ampliação da categoria gênero tal como a compreendo, em contexto de pós-modernidade, implica o esforço de não essencializála, mas percebê-la sob a influência de fatores diferentes que a compõem.

Antonio F. Pierucci, ${ }^{23}$ ao analisar as diferentes "ondas" do feminismo, destaca que a década de 1980 apresentou uma nova vertente do debate teórico feminista. A tendência era de que não mais se explorassem apenas os conflitos entre homens e mulheres, mas os conflitos entre as mulheres, considerando a "multiplicidade feminina". Além disso, essa nova corrente exigia mais autocrítica para as próprias feministas e um certo reconhecimento do que seria uma "heterogeneidade interna" das mulheres que exigia uma abordagem mais multifacetada. ${ }^{24}$

Nesse sentido, cabe aos analistas uma sempre continuada busca da compreensão dos contextos onde determinadas mulheres desejem assumir lugares representativos e outras, ao contrário, optem pelo lugar social de uma quase vertiginosa não-notoriedade pública (ser "do lar", por exemplo). Esse nem sempre é um exercício simples para os que desejariam a consolidação de um movimento sempre reivindicatório por parte das mulheres em oposição aos homens.

\section{O lugar da mulher na lgreja e o sacerdócio feminino - visão das moças}

Em julho de 2004 o Vaticano lançou mais uma Carta ${ }^{25}$ a respeito do tema da mulher na lgreja e as posições se mantêm conservadoras quanto à ordenação sacerdotal feminina; ao divórcio, e ainda quanto à manutenção da virgindade até o casamento. Para a lgreja Católica, temas ligados à moralidade sexual não são passíveis de discussão e fazem parte de um posicionamento tradicional construído por grandes pensadores como Santo Agostinho (séc. IV e V) e Tomás de Aquino (séc. XIII). Este último promoveu uma supervalorização da virgindade ao afirmar que aqueles que se mantivessem virgens e castos receberiam uma recompensa celestial de $100 \%$; viúvos e viúvas de $60 \%$ e casados de $30 \%{ }^{26}$

\footnotetext{
${ }^{22}$ Aprecio especialmente a conceituação de Agnes Heller sobre pós-modernidade. Para essa autora, "a pós-modernidade não é nem um período histórico nem uma tendência cultural ou política de características bem definidas. Pode-se em vez disso entendê-la como o tempo e o espaço privado-coletivos, dentro do tempo e espaço mais amplos da modernidade, delineados pelos que têm problemas com ela e interrogações a ela relativas, pelos que querem criticá-la e pelos que fazem um inventário de suas conquistas, assim como de seus dilemas não resolvidos" (HELLER e FEHER, 1998, p. 11).

${ }^{23}$ PIERUCCI, 1999.

${ }^{24}$ Explicitando essa nova tendência das teorias feministas, Pierucci afirma: "não dava mais para ficar isolando o gênero das outras determinações sociais, das outras variáveis independentes, das outras pertenças coletivas das mulheres [...] as análises de gênero não podem ignorar o fato histórico-empírico-existencial de que a experiência (ou a identidade) de gênero está intrinsecamente vinculada com outros aspectos significativos da posição social e da pertença cultural - a classe e a raça, pelo menos!" (PIERUCCI, 1999, p. 131). Algumas autoras destacadas por Pierucci como pertencentes a essa nova vertente são Linda Gordon, Ellen DuBois, Vicki Ruiz e Elizabeth Spelman.

${ }^{25}$ Joseph RATZINGER, 2004.

${ }^{26}$ RANKE-HEINEMANN, 1996, p. 198.
} 
O discurso tanto dos rapazes quanto das moças sobre o tema da ordenação sacerdotal, é absolutamente situado no tempo e aggiornatto a partir de reflexões colocadas para os sujeitos de hoje, enlaçados pelo movimento de construção e reconstrução de suas identidades.

Entre as entrevistadas, dez se mostraram favoráveis à ordenação feminina, cinco são contrárias, quatro se mostraram divididas quanto ao tema e uma não soube opinar. Desse modo, verifica-se que a grande maioria das vocacionadas manifestou-se favoravelmente à ordenação de mulheres, embora isso não signifique necessariamente que elas reivindicariam para si a condição de sacerdotisas, já que, entre as dez favoráveis, sete se candidatariam ao exercício do sacerdócio feminino. Por outro lado, a nãoreivindicação se inscreve no bojo da discussão que levantamos anteriormente sobre a condição feminina e sua heterogeneidade (as condições femininas). As mulheres não constituem, portanto, uma categoria hermética, mas são sujeitos sociais carregados de idiossincrasias e marcados por histórias singulares. Tais idiossincrasias, constituídas pela realidade sociocultural de onde provêm, irão dar tons diferenciados a seus discursos.

Mônica posiciona-se de uma forma mais crítica e enfatiza o caráter hierárquico da Igreja. Afirma que se candidataria ao exercício do sacerdócio, caso fosse permitido às mulheres exercê-lo, e critica o papel suplementar que muitas vezes é delegado pelos padres às religiosas. Mônica é simpatizante e foi participante da Renovação Carismática Católica (RCC), movimento que a ajudou em determinado momento da vida a vencer a depressão.

[...] a mulher não poder celebrar, eu acho isso errado, porque quem... na Bíblia não tá escrito que mulher não pode celebrar uma missa, não pode consagrar uma hóstia, não está escrito isso em lugar nenhum. Jesus, ao menos que eu conheça.[...] até onde eu já li não tem, mas eu ainda vejo a Igreja muito hierárquica, entendeu? Eles dão pras mulheres aquilo que eles não dão conta de fazer, porque o que eles dão conta de fazer é deles, entendeu? [...] Eu mesmo me candidataria, mas não pra ficar numa paróquia que tenha padre, eu me candidataria para uma paróquia que não tivesse padre (Mônica, 23, noviça).

A ocorrência de distribuição por parte do clero de funções ou tarefas às mulheres nos espaços eclesiais corrobora a existência de um campo de forças muitas vezes velado, reproduzido e reforçado por meio das dinâmicas relacionais estabelecidas no cotidiano. Essas dinâmicas podem produzir naturalizações da ordem estabelecida e, nesse sentido, legitimar e solidificar estruturas simbólicas de poder, tal como nos mostrou Pierre Bourdieu ${ }^{27}$ em sua análise sobre o poder político e o poder religioso. O autor demonstra que o efeito da "absolutização do relativo e de legitimação do arbitrário" ocorre, entre outros aspectos, pela imposição de um modo de pensamento hierárquico, naturalizador das relações de ordem.

O discurso de Decir - também favorável à ordenação feminina - enfatiza o aspecto da igualdade de direitos, ${ }^{28}$ ainda que verbalizando, tal como vários seminaristas, o papel da tradição. Na verdade, essa jovem reconhece a hierarquia como modelo constitutivo

\footnotetext{
27 BOURDIEU, 1999, p. 71.

${ }^{28}$ Antonio Pierucci faz notar que a "primeira onda" do feminismo não usava a palavra diferença, já que as teóricas estavam empenhadas na conquista de oportunidades, postos e direitos iguais entre homens e mulheres. É na "segunda onda" que os círculos acadêmicos irão trabalhar com o conceito de "diferença de gênero" quando se passa a estabelecer a diferenciação entre sexo e gênero, sendo o sexo o dado biológico e gênero a construção social. Para Pierucci, o principal risco do enfoque sobre a diferença entre os sexos é o essencialismo que pode terminar em "fixação essencializante de uma diferença". Esse posicionamento dificultaria, na visão desse autor, a articulação das diferenças entre "mulheres" e "Mulher" (PIERUCCI, 1999, p 122-129).
} 
da lgreja e justifica esse modelo pela tradição. Tal reconhecimento, todavia, não a impede de expressar seu ponto de vista favorável ao sacerdócio feminino.

Gilda considera que ainda há muito a avançar na temática de gênero e acredita na existência de discriminação da mulher na lgreja Católica. Seu discurso destaca: busca de status e poder por parte dos padres; formação desigual para vocacionados e vocacionadas nos institutos e seminários, que acabaria privilegiando a formação intelectual para os homens e emocional para as mulheres.

Então eu vejo muito forte essa questão do clericalismo, a questão da discriminação da mulher enquanto religiosa, da mulher enquanto leiga [...]. Porque eu acho que precisa espaço, acho que se precisa abrir muito pra isso. E também eu vejo como uma falha, daí até de alguns institutos, é a questão da formação. A formação do seminarista ela cai muito na questão intelectual dos estudos, que eu acho que é fundamental, mas esquece de trabalhar o humano, as questões psicológicas, as questões emocionais e afetivas do menino que entra. E daí vira um grande teólogo, talvez um grande filósofo. Mas dele mesmo ele não entende, daí fica difícil entender o povo também na sua vivência, nos seus sentimentos (Gilda, 22, noviça).

Tendo em vista que a exigência do aprendizado formal de Filosofia e Teologia ocorre apenas para os rapazes que desejam ingressar na vida sacerdotal, os institutos e congregações religiosas femininas não priorizam a formação intelectual para as moças. O aprendizado de disciplinas clássicas se dá de modo mais esporádico, sem muita formalidade e ao mesmo tempo a partir das mais diferenciadas iniciativas dos formadores, tais como os cursos de formação oferecidos pela Conferência dos Religiosos do Brasil, palestras sobre temas específicos da Vida Religiosa, ministradas geralmente por agentes eclesiais, cursos promovidos pela diocese, etc.

Celina não realiza uma crítica no que se refere à não-ordenação feminina; porém, não considera que as relações de gênero na lgreja sejam igualitárias.

Eu vejo assim, os direitos pra mim devem ser iguais, não ter diferenças entre o homem e a mulher. Mas como não foi permitido pela Igreja de a mulher ser sacerdotisa, eu acolho numa boa... eu acho que às vezes tem sacerdote que não aceita a mulher nem mesmo sendo ministra da Eucaristia. Eu acho isso errado e acho que não tem nada a ver, nem ser ministra! Acho isso um absurdo, porque ser ministro da Eucaristia não tem nada a ver, ser homem ou mulher. Mas quanto a ser sacerdotisa, o padre ser sacerdote, a mulher ainda não, eu acolho, porque é uma ordem que a Igreja deixou, é por lei da lgreja e eu acho que a gente como Igreja também deve acolher, se é da Igreja, por que não? (Celina, 21, noviça).

Aqui se observa tanto uma aceitação da norma quanto uma simultânea contestação desta. Note-se, entretanto, que Celina questiona a autoridade do padre, mas não a prescrição eclesiástica sobre a ordenação de mulheres. Essa jovem avalia que os direitos devem ser iguais, mas parece não associar a questão dos direitos entre homens e mulheres com o exercício de determinadas funções, ou melhor, ela reproduz o discurso que define cargos para homens e mulheres, tendo em vista sua concordância com o fato de que as mulheres sejam ministras da Eucaristia, ${ }^{29}$ e mostra seu incômodo com os padres que não permitem o exercício dessa função pelas mulheres.

29 Função que pode ser exercida tanto por homens quanto por mulheres no catolicismo e contempla basicamente a atividade de levar a hóstia aos doentes e/ou distribuí-la nas missas. 


\section{Considerações finais}

O duplo movimento que se constata no discurso dos rapazes a respeito das relações de gênero na lgreja Católica é marcado pela situação ou lugar institucionalmente ocupado pelos/as jovens vocacionados/as. Assim, o estudo qualitativo sugere que ser vocacionado para o exercício da função de sacerdote e ser vocacionada para ser freira supõem diferenciação na formação, na relação institucional e na relação com o mundo leigo, ${ }^{30} \mathrm{e}$ como conseqüência pode significar posicionamentos mais ou menos divergentes diante da Igreja Católica e sua constituição doutrinária.

Esse duplo movimento contempla basicamente o dilema do sujeito individual e do sujeito coletivo, ou seja, representante e constituinte de um sistema hierárquico que o abriga. Desse modo, a orquestração das configurações das identidades colocadas pelos sistemas religiosos, pelas demandas individuais de sentido e pelas narrativas de grupos específicos com ressonância que ultrapassa uma dada sociedade (tal como as narrativas feministas) não se torna uma tarefa simples.

Como assinala Charles Taylor, há uma incontornabilidade nas configurações modernas de identidade que conduzem o indivíduo a uma "disjunção relativamente aberta de atitudes". ${ }^{31}$ Esse mesmo autor nos adverte que o traço comum a todas as novas configurações é o de que nenhuma será partilhada por todos e os posicionamentos frente a elas terão sempre um caráter hesitante. Ora os jovens tentam garantir a legitimidade dos argumentos institucionais, ora os contestam ou relativizam, tendo em vista a existência de outros discursos também legitimados por um corpo social mais amplo.

O movimento dos sujeitos que aderem à vocação sacerdotal e religiosa no catolicismo é decisivo para a reflexividade institucional. Entretanto, levando-se em conta a existência de blocos de força antagônicos na Igreja Católica, mais especificamente na hierarquia eclesiástica, não se vislumbra, em curto prazo, mudanças sólidas que se convertam em aparatos legítimos diante dos gêneros feminino e masculino na lgreja. Ainda assim, deve-se levar em conta o potencial profético (no sentido dado por Weber) da vocação religiosa feminina, capaz de confrontar - em maior medida que a masculina mecanismos institucionais que monopolizam a produção religiosa.

O posicionamento de alguns rapazes acerca das relações de gênero na Igreja tende a inclinar-se para uma manutenção do status quo, seja relativizando a não-atribuição de um lugar às mulheres na hierarquia a partir da defesa da tradição, seja positivando e valorizando a presença feminina nas Igrejas a partir da atuação das mulheres em alguns ministérios (Eucaristia, Celebração da Palavra) e em atividades paroquiais. Esta última atitude - a valorização da presença da mulher nas Igrejas - é estratégica e fortalece a manutenção da norma que inviabiliza o acesso das mesmas ao sacerdócio, sobretudo pelo argumento de que elas já teriam seus lugares devidamente distribuídos no mundo eclesial e, mais, já possuiriam um reconhecimento eclesiástico legitimado através dos vários documentos do Magistério que tratam do tema valorizando a contribuição feminina às lgrejas.

Atribuir um lugar às mulheres, entretanto, não representa igualdade de condições na esfera hierárquica. Ao mesmo tempo, pode não significar uma necessária subordinação feminina tendo em vista a existência de grupos de mulheres no catolicismo que atuam de

\footnotetext{
${ }^{30}$ A palavra leigo é originária do latim laicu e semanticamente significa os que pertencem ao povo cristão e não à hierarquia eclesiástica; outro significado remete à não-especialização, portanto permanência em estado laico. Pierre Bourdieu conceitua os leigos como aqueles que são destituídos do capital religioso (BOURDIEU, 1999, p. 39) e Pedro Ribeiro Oliveira menciona que a palavra era adotada no modelo de cristandade que fazia distinção entre a nobreza, o clero e os leigos (OLIVEIRA, 2003, p. 184).

${ }^{31}$ TAYLOR, 1997, p. 15-40.
} 
forma mais questionadora diante da hierarquia. Ainda assim, a distribuição da autoridade na lgreja Católica não tem se alterado de forma significativa a partir dos questionamentos das mulheres, sejam elas leigas, sejam religiosas.

Destaque-se que, neste estudo, alguns rapazes se posicionaram de modo menos ortodoxo quanto ao tema, identificando limites no relacionamento entre padres e freiras e encarando a restrição institucional ao sacerdócio feminino como uma norma passível de revisão. Alguns elementos que parecem influenciar o posicionamento dos seminaristas de modo mais determinante são a linha ideológica do instituto religioso ao qual pertencem, no caso dos religiosos, e da diocese, no caso dos diocesanos e, ainda, o tempo de formação.

Por fim, o estudo demonstra que as assimetrias de gênero no corpo hierárquico do catolicismo são percebidas por seus novos agentes religiosos, mas questionadas majoritariamente pelas moças que se candidatam à Vida Religiosa nos conventos. Os rapazes, futuros padres, mostraram-se cautelosos nas críticas, ainda que não tenham indicado justificativa teológica plausível para a posição do Vaticano. Foram poucos os que assumiram posicionamentos mais críticos diante do tema da não-ordenação feminina. Caberia investigar ainda se o perfil de seminaristas aqui identificados, mais afinados com as prescrições romanas, pode ser estendido para o âmbito nacional. Se futuras investigações demonstrarem que sim, tornar-se-á cada vez mais um "horizonte perdido" a possibilidade de as mulheres tornarem-se sacerdotisas na Igreja Católica.

\section{Referências bibliográficas}

BERLIS, Ângela. "A ordenação das mulheres: um teste para a conciliaridade". Concilium, Petrópolis/RJ: Vozes, n. 279, p. 103-111, 1999.

BHABHA, Homi K. O local da cultura. Belo Horizonte: UFMG, 1998.

BOURDIEU, Pierre. A economia das trocas simbólicas. São Paulo: Perspectiva, 1999.

BUTLER, Judith. "Variações sobre sexo e gênero: Beauvoir, Wittig e Foucault". CORNELL, Drucilla; BENHABIB Seyla (Coords.). Feminismo como crítica da modernidade. Rio de Janeiro: Ed. Rosa dos Tempos, 1987. p. 139154.

CERIS. Perfil do presbítero brasileiro. Relatório conclusivo. Rio de Janeiro. Disponível em: http//: www.ceris.org.br. Acesso em: mar. 2004.

DE LAURETIS, Teresa. "A tecnologia de gênero". Tendências e impasses: o feminismo como crítica da cultura. HOLLANDA Heloisa B. (Org.). Rio de Janeiro: Rocco, 1994. p. 209-242.

DUBY, Georges. Eva e os padres: damas do século XII. São Paulo: Companhia das Letras, 2001.

FERNANDES, Sílvia R. A. "Vinho novo em odres velhos?" Uma análise da Vida Religiosa feminina na modernidade contemporânea. 1999. Dissertação (Mestrado em Ciências Sociais) Instituto de Filosofia e Ciências Sociais, UERJ, Rio de Janeiro.

. "Ver para crer: as novas investidas do catolicismo no Brasil através do Padre Marcelo Rossi". In: CONFERÊNCIA DO CESNUR, 14., Riga, Latvia. Letonia, 2000. Trabalho apresentado. Disponível em: http://www.cesnur.org/testi.htm .

"Diferentes olhares, diferentes pertenças: Teologia da Libertação e MRCC". REVER - Revista Eletrônica de Estudos da Religião, São Paulo: PUC, n. 3, 2001. Disponível em: http://www.pucsp.br/rever/rv3.

"Catolicismo, massa e revival: Padre Marcelo Rossi e o modelo kitsch". Cadernos de Campo, São Paulo: USP, n. 11, ano 12, p. 87-98, 2003.

"Ser padre pra ser santo; Ser freira pra servir": a construção social da vocação religiosa - uma análise comparativa entre rapazes e moças no Rio de Janeiro. 2004a. 
Tese (Doudorado em Ciências Sociais) - Instituto de Filosofia e Ciências Sociais, UERJ, Rio de Janeiro.

. Cattolicesimo, massa e revival: Padre Marcelo Rossi e il modello kitsch. Rivista Religioni e Societá, Firenze: Firenze University Press, n. 48, p. 65- 74, 2004b.

FLAX, Jane. "Pós-modernismo e relações de gênero na cultura contemporânea". In: Heloisa B. Hollanda. (Org.). Pós-modernismo e política. Rio de Janeiro: Rocco, 1992. p. 177249.

GEBARA, Ivone. Rompendo o silêncio: uma fenomenologia feminista do mal. Petrópolis, RJ: Vozes, 2000.

Vida Religiosa: da teologia patriarcal à teologia feminista: um desafio para o futuro. São Paulo: Paulinas, 1992.

GIDDENS, Anthony. Modernidade e identidade. Rio de Janeiro: Jorge Zahar Ed., 2002.

GIDDENS, Anthony et al. Modernização reflexiva: política, tradição e estética na ordem social moderna. São Paulo: UNESP, 1997.

HELLER, Agnes; FEHÉR, Ferenc. A condição política pós-moderna. Rio de Janeiro: Civilização Brasileira, 1998.

MACHADO, Maria D. C.; FERNANDES, Sílvia R. A. Carismáticos e pentecostais: a dimensão religiosa dos movimentos revivalistas. Magis Cadernos de Fé e Cultura, Rio de Janeiro: Centro Loyola de Fé e Cultura, PUC, n. 37, p. 151-167, 2000.

OLIVEIRA, Pedro Ribeiro de. "A teoria do trabalho religioso em Pierre Bourdieu". In: TEIXEIRA, Faustino (Org.). Sociologia da religião. Petrópolis, RJ: Vozes, 2003. p. 177-197.

PIERUCCI, Antonio F. O desencantamento do mundo: todos os passos do conceito em Max Weber. São Paulo: USP, 2003.

Ciladas da diferença. São Paulo: USP/Ed. 34, 1999.

QUINTEIRO, Maria da Conceição. "Contribuições para os estudos das relações entre os gêneros". Revista Plural, São Paulo: USP, n. 3, p. 122-134, 1996.

RANKE-HEINEMANN, Uta. Eunucos pelo Reino de Deus: mulheres, sexualidade e Igreja Católica. Rio de Janeiro: Record, Rosa dos Tempos, 1996.

RIBEIRO, Zilda Fernandes. A mulher e seu corpo: magistério eclesiástico e renovação da ética. Aparecida, SP: Editora Santuário, 1998.

ROSADO NUNES, Maria José F. Vida Religiosa nos meios populares. Petrópolis, RJ: Vozes, 1985.

"Mulheres na Igreja Católica: elementos para uma crítica do poder religioso". In: VIII JORNADAS SOBRE ALTERNATIVAS RELIGIOSAS NA AMÉRICA LATINA, 8., 1998, São Paulo. Trabalho apresentado na mesa-redonda MR 11 - "Mulher, gênero e poder religioso". São Paulo, 1998.

"A Igreja Católica sob debate público". Revista Conciencia, La Paz, Bolívia: CDD, v. XIII, n. 5, p. 8-11, 2002.

SOUZA, Luiz Alberto G. Do Vaticano Il a um novo Concílio? O olhar de um cristão leigo sobre a Igreja. São Paulo: Loyola, 2004.

STRATHERN, Marilyn. The Gender of the Gift. Berkley: University of Califórnia Press, 1988.

TAYLOR, Charles. As fontes do Self: a construção da identidade moderna. São Paulo: Loyola, 1997.

. Argumentos filosóficos. São Paulo: Loyola, 2000. p. 241-274.

WEBER, Max. "Rejeições religiosas do mundo e suas direções". In: GERTH, Hans H.; WRIGHT MILLS, Charles (Orgs.). Ensaios de sociologia. Rio de Janeiro: Ed. Guanabara Koogan S/ A, 1982. p. 371-409.

. Economia e sociedade: fundamentos da sociologia compreensiva. Brasília: Ed. da UnB, 1998. p. 279-418. 


\section{Documentos e declarações da Igreja Católica}

CNBB. Diretrizes básicas da formação dos presbíteros da lgreja no Brasil. Doc. n. 55, 1994 . Vida e ministério do presbítero: pastoral vocacional. Doc. n. 20. São Paulo: Paulinas, 1981.

DOCUMENTOS PONTIFÍCIOS. Sacerdócio de mulheres? Petrópolis: Vozes, 1996. n. 268.

JOÃO PAULO II. Mulieris dignitatem, 1988. Disponível em: http://www.vatican.va. Acesso em: 25 out. 2002.

Ordinatio sacerdotalis, 1994. Disponível em: http://www.vatican.va. Acesso em: 12 set. 2003 2003.

Carta às mulheres, 1995. Disponível em: http://www.vatican.va. Acesso em: 12 set.

RATZINGER, Joseph. Carta aos bispos da Igreja Católica sobre a colaboração do homem e da mulher na Igreja e no mundo, 2004. Disponível em: http//:www.vatican.va/ roman_curia/congregations. Acesso em: 15 ago. 2004.

The Denial of Female Ordination: Gender Asymmetries in The Catholic Church from The Point of View of Prospective Nuns and Priests

Abstract: The denial of female ordination is approached in this paper from the perspective of young men and women that desire to enter convents. This is a sociological and qualitative study that comparativily analyses the perceptions of young men and women of gender relations in the Catholic Church. Their testimonies clearly show the existence of gender inequality in the church"s hierarchy and reveal that the young women have a tendency to be more critical and inquisitive, while the young men tend to maintain the status quo.

Key Words: Catholicism, gender, religious vocation. 